\title{
Surface measurements of hydraulic properties in an irrigated soil using a disc permeameter
}

\author{
A. Comegna, G. Severino \& A. Sommella \\ Department of Agricultural Engineering and Agronomy, \\ University of Naples Federico II, Italy
}

\begin{abstract}
With a view to determining in situ the hydraulic properties of soils with macropores, disc permeameters are currently used which allow evaluation over time of water infiltration values and selective activation of preferential flow paths through variation in water supply potential imposed on the soil surface. It is then possible, through the resolution of wetting 3-D flow fields, to obtain soil hydraulic characteristics at or near saturation. In this study two different methods to calculate the hydraulic conductivity of a structured soil, based on disc-permeameter data, are compared. Laboratory core measurements based on the crust method are also used in the comparison. The first method based on a single disc at the same location with multiple water supply potentials gave results that are accurate, whereas the second method based on a single disc at different locations and water supply potentials gave biased values. The advantage of the examined equipment and procedures is that they are simple to apply and use. Moreover, useful applications of disc-permeameter techniques also consist in the measurement of soil structural parameters, especially pore size and areal macroporosity under irrigation practice.
\end{abstract}

Keywords: 3-D infiltration, disc permeameter, unsatured flow parameters.

\section{Introduction}

In recurrent open field situations, above all in soil surface layers, structural and textural variations as well as various geometric characteristics of the matrix may entail significant space-time variations in the processes of water and solute movement.

The action of raindrops, the boundary forces provoked by surface flows and chemo-physical factors linked to water quality may, on the soil surface, lead to 
disaggregation of the aggregates and the formation of less permeable crusts which condition the infiltration process.

Moreover, the presence of surface cracks which characterizes many verticsoils, and the proliferation of macroporosity, caused by the ground fauna and by the great presence of roots, may create vertical by-passes and preferential flow paths which produce a transfer of the solutes during rain or irrigation, by means of infiltration water. Such a transfer occurs more rapidly than the advance of the average moisture front, with a consequent alteration of the space-time scales of the process of mass exchange between the various porous domains of the matrix (Beven and Germann, [1]).

In the light of the above mechanisms, the danger of widespread pollution processes has been confirmed with regard to particularly vulnerable underground water resources due to the extent of the boundary surface directly exposed to contributions from agricultural land use (Thomas and Phillips, [2]; White, [3]). Today, numerous mathematical models based on the solution of Richards' equation allow the numerical simulation of water and pollulant transfer in the vadose zone and thus may be essential instruments for assessing environmental pollution. However, the solutions offered by such models may contain considerable errors in the case of structured soils with heterogeneous pore systems which cannot be adequately described by the generally used unimodal retention and hydraulic functions. In such cases, for characterizing the flow regime, it is essential to separate the flow through macropores from the one through the soil matrix (Bouma, [4]). Recognition of this dichotomy is important because the properties of the macroporous system tend to dominate the infiltration process at and near saturation, while drainage, redistribution and root water uptake depend on those hydraulic properties which reflect the nature of the matrix.

Given the complexity of the problem, specific macropore models have recently been set up (Jarvis et al., [5]; Chen and Wagenet, [6]; Gerke and van Genuchten, [7]) which may more simply be considered as dual-porosity models. Implementation of such models requires new technologies and, because of the ephemeral nature of macropores, a new class of experiments to be conducted, if possible, in the field, so as to obtain input data for quantifying soil hydraulic properties, macropore distribution and spatial variation of macropores.

Various methods to obtain macropore parameters have been set up, such as tracer-breakthrough curves, computerized tomography, dye-staining and sectioning (Bouma and Dekker, [8]; Warner et al., [9]). However, in most cases such methods require undisturbed soil samples and they cannot be easily transferred to the open field. More simple methods, as recently suggested, are based on measuring unconfined infiltration rates with a disc permeameter (Perroux and White, [10]; Watson and Luxmoore, [11]; Ankeny et al., [12]) or a surface crust to restrict flow rates into the soil (Booltink et al., [13]). By offering slight hydraulic resistance to water movement, discs and crusts allow a water supply potential $\mathrm{h}$ to be applied at the soil surface, with a negligible head loss. By appropriately choosing the resistance value and ensuring that $\mathrm{h}$ is only -0.01 to $-0.02 \mathrm{~m}$, an acceptable approximation of soil hydraulic conductivity is 
obtained, which excludes the macropore system. It is thus possible, by the resolution of the 3-dimensional moisture flow field, to obtain soil hydraulic properties for water content values near saturation.

Finally, it is worth mentioning particular calculation methods proposed in the literature and set up for estimating hydraulic conductivity from disc permeameter data. Among others, the most commonly used are those proposed by White and Sully [14] and by Ankeny et al. [12]. Such methods vary in complexity and simplificatory assumptions, as well as having different advantages and limitations.

In order to further our knowledge in this field, this paper presents an application of disc permeameter equipment, analysis techniques and procedures in the examination of field hydraulic conductivity of a structured soil.

In section 2 the constructional characteristics of the disc permeameter equipment are presented (2.1); the theoretical underpinning for using the disc permeameter to infer hydraulic conductivity are illustrates (2.2). Section 2.3 illustrates the physical properties of the soil in question, the methods of the infiltration test and the calculation procedures used. Finally, some considerations are made and several conclusions drawn.

\section{Materials and methods}

\subsection{Disc-permeameter}

The apparatus used to impose Dirichlet's boundary condition $h_{0} \leq 0$ at the soil surface, in which $h_{0}$ is the water supply potential, are called tension infiltrometers or disc permeameters in the literature.

Following the design of Perroux and White [10], a prototype permeameter (figure 1) was set up jointly by the Institute of Agricultural Hydraulics of the University of Naples.

The permeameter in question consists of a bubble tower which may be considered a Mariotte double regulator connected to a perspex disc $200 \mathrm{~mm}$ in diameter covered by a porous nylon membrane with air entry value of approximately $0.25 \mathrm{~m}$.

The first regulator allows us to apply via the membrane a constant water supply potential which can be controlled by adjusting the water level inside. The second regulator, which functions as a reservoir by means of a graduated scale, allows infiltration water volumes to be evaluated in time.

The experimental observations which may be carried out with such a device necessitate, between the base of the disc and the soil surface, that there is adequate hydraulic contact by means of a thin sand stratum previously wetted up to a volumetric water content close to 0.01 .

\subsection{Theory}

The theoretical foundations for using a disc permeameter to infer soil hydraulic properties have been discussed in detail elsewhere (Perroux and White, [10]; Smetten and Clothier, [15]). Only the salient features are recalled below. 


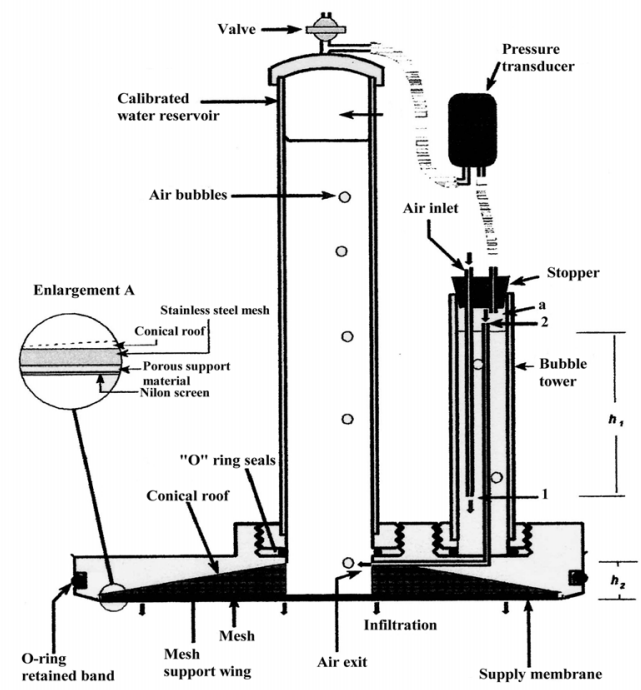

Figure 1: Schematic diagram of disc permeameter.

\subsubsection{Sorptivity}

The water flow emanating from a disc source according to Dirichlet's boundary condition:

$$
h=h_{0} \leq 0 ; \quad z=0 ; \quad t>0
$$

where $\mathrm{h}_{0}$ is the water supply potential, $\mathrm{z}$ is the depth and $\mathrm{t}$ is the time, is initially controlled by soil capillarity (Philip, [16]):

$$
\lim _{t \rightarrow 0}\left[\frac{Q(t)}{\pi r^{2}}\right]=1 / 2 S_{0} t^{-1 / 2}
$$

in which $Q$ is the flow rate $\left[\mathrm{L}^{3} \mathrm{~T}^{-1}\right.$ ] from the disc source, $t$ the time, $r$ the radius of the source [L], $S_{0}=S\left(h_{0}, h_{n}\right)$ the sorptivity $\left[\mathrm{LT}^{-1 / 2}\right]$ and $h_{0}$ and $h_{n}$, respectively, the supply and initial water potential [L].

Integrating eqn. 1 with regard to $t$, we obtain:

$$
I=S_{0} t^{1 / 2}
$$

in which $I$ is the cumulated infiltration [L].

For lower time values starting from infiltrated water volumes, $\mathrm{S}_{0}$ may be simply deduced from the slope of $I$ with regard to $\sqrt{t}$.

The geometric time scale of Philip [16], $t_{\text {geom }}$, may be used to evaluate when the geometric dominance of disc source should have been established. This time is considered to be:

$$
t_{\text {geom }}=\left[\frac{r \Delta \theta}{S}\right]^{2}
$$

in which $\Delta \theta=\theta_{0^{-}} \theta_{n} ; \theta_{0}$ and $\theta_{n}$ are, respectively, water content values corresponding to the supply and initial water potential. 


\subsubsection{Steady state flow}

The water flow rate will reach a stationary value henceforth termed $Q_{\infty}$ for greater time values (Philip [17]).

In the case of multi-dimensional flow processes, Philip [18] showed that a characteristic time scale $t^{*}$ for the steady state flow rate is that for which the flow from the source is 1.05 times the steady flow rate. His calculations show that when the characteristic size of source $r$ equals or exceeds the macroscopic capillary length scale, $\lambda_{c}$, an "innate soil length scale" as defined by Raats [19], then it may be held that $t^{*}=t_{\text {grav }}$, with $t_{\text {grav }}$ given by:

$$
t_{\text {grav }}=\left(\frac{S}{k_{0}}\right)^{2}
$$

The above findings were recently confirmed by Warrick's studies [20]. Physically, $t_{\text {grav }}$ represents the time in which the effects of gravity equal the effects of capillarity (Philip, [16]).

In the case of "alpha" soils, that is those soils in which hydraulic conductivity takes the exponential form (Gardner, [21]):

$$
k=k_{0} \exp (\alpha h)
$$

in which $k_{0}$ is the saturated hydraulic conductivity and $\alpha$ a constant equivalent to $\lambda_{c}^{-1}$, Wooding [22] showed that the steady flow from the source, for an assigned value of water supply potential, may be approximated with sufficient accuracy by the following expression:

$$
\frac{Q_{\infty}}{\pi r^{2}}=\Delta k\left[1+\frac{4 \lambda_{c}}{\pi r}\right]
$$

in which $\Delta k=k_{0}-k_{n}$.

Subsequently, White and Sully [14] demonstrated that between the characteristic length scale $\lambda_{c}$, sorptivity and hydraulic conductivity, there may be the following type of relation:

$$
\lambda_{c}=\frac{b S^{2}}{\Delta \theta \Delta k}
$$

in which $b(1 / 2 \leq b \leq \pi / 4)$ is a shape factor frequently set at approximately 0.55 for agricultural soils.

If, as happens in many open field situations, it may be assumed that: $\Delta k=k_{0}=k$ and if we substitute eqn. (6) in (5), the following simplified expression is obtained:

$$
\frac{Q_{\infty}}{\pi r^{2}}=k+\frac{2.2 S^{2}}{\Delta \theta \pi r}
$$

An alternative approach based only on Wooding's solution is possible when we know the flows $Q_{\infty}$ corresponding to the different $\mathrm{r}$ values of the source (Scotter et al., [23], Smetten and Clothier, [15]). This approach allows $k$ and $\lambda_{c}$ to be evaluated directly, thereby solving two type (5) equations. 
The same principle may be applied for a single $r$ of the disc source but with infiltration measurements at multiple potentials (Ankeny, [12]). In particular, in this case, if the flow is measured with a single disc source at two pre-established potential values $h_{1}$ and $h_{2}$, two type (5) equations are obtained, which may be solved simultaneously, thereby supplying:

$$
\begin{aligned}
& k_{1}=\frac{Q_{1}}{\pi r^{2}+2 \Delta h r\left(1+\frac{Q_{2}}{Q_{1}}\right)\left(1-\frac{Q_{2}}{Q_{1}}\right)} \\
& k_{2}=\frac{Q_{2} k_{1}}{Q_{1}} \\
& \lambda_{c}=\frac{\Delta h\left(k_{1}+k_{2}\right)}{2\left(k_{1}-k_{2}\right)}
\end{aligned}
$$

in which $Q_{1}$ and $Q_{2}$ are, respectively, $Q_{\infty}$ at $h_{1}$ and $h_{2}$.

\subsection{Soil site and measurements}

Infiltration tests were conducted in the spring of 1994 at the experimental farm of the University of Basilicata near Corleto (Potenza, Italy) on a bare soil which had undergone minimum tillage during the winter. The dominant soil at the experimental site is sandy clay with a clay content of approximately $30 \%$ as shown in figure 2.

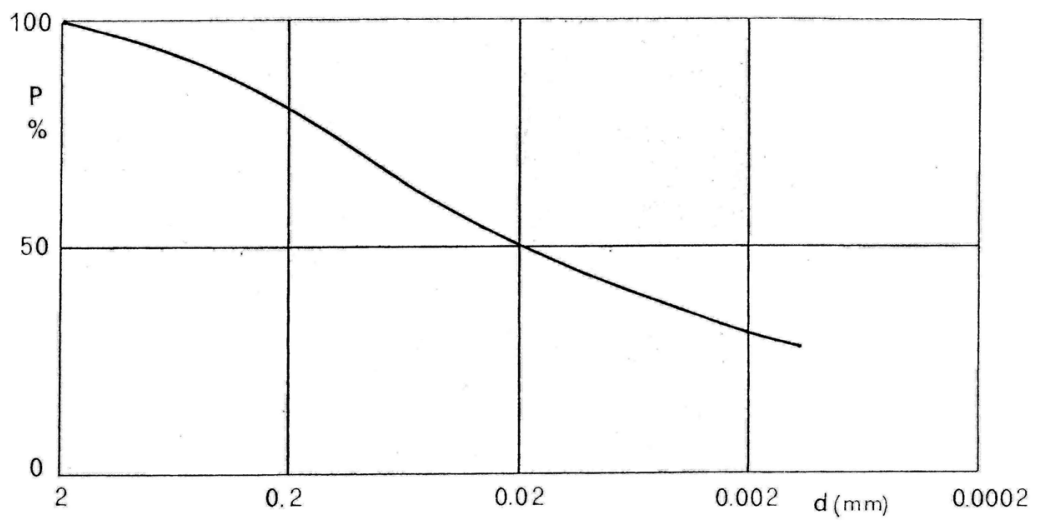

Figure 2: $\quad$ Particle size distribution of examined soil.

From the pedological point of view, the soil may be classified as "vertic ustorthens" according to the USDA classification system. Other important properties comprise moderate permeability and the vertic traits of clayey land which cracking renders quite appreciable during the summer. 
At the test location one $\left(1 \times 1 \mathrm{~m}^{2}\right)$ plot was isolated and subdivided into 4 equal subplots of $0.5 \times 0.5 \mathrm{~m}^{2}$. To determine soil hydraulic conductivity with White and Sully's method [14], three water supply potentials were used $(-0.02 ;-0.06 ;-0.10$ $\mathrm{m})$, each in a single subplot.

According to the Ankeny et al. method [12], in the 4th subplot the disc permeameter was not moved for trials at the three potentials $(-0.06 ;-0.04 ;-0.02$ $\mathrm{m})$. With this method, steady state flows were measured in an ascending sequence of supply potentials: first with a $-0.06 \mathrm{~m}$ water supply potential followed by -0.04 and $-0.02 \mathrm{~m}$.

In each subplot, three undisturbed soil samples, $4.8 \mathrm{~cm}$ in diameter and 2.8 $\mathrm{cm}$ in height, were taken from the soil surface before and after the infiltration tests in order to measure bulk density and volumetric surface water content $\theta$ corresponding to $h_{0}$ and $h_{l}$. The mean dry bulk density of the first $2.8 \mathrm{~cm}$ of soil measured on undisturbed soil samples was estimated at $1.198 \mathrm{~g} / \mathrm{cm}^{3}$ and the standard deviation at $0.05 \mathrm{~g} / \mathrm{cm}^{3}$.

Following disc permeameter measurements, the soil was allowed to drain for about three hours and then an undisturbed soil sample $15 \mathrm{~cm}$ in diameter and 20 $\mathrm{cm}$ high was dug out of the 4th subplot immediately below the porous disc, to measure the hydraulic conductivity in the laboratory with the crust method (Booltink et al., [13]).

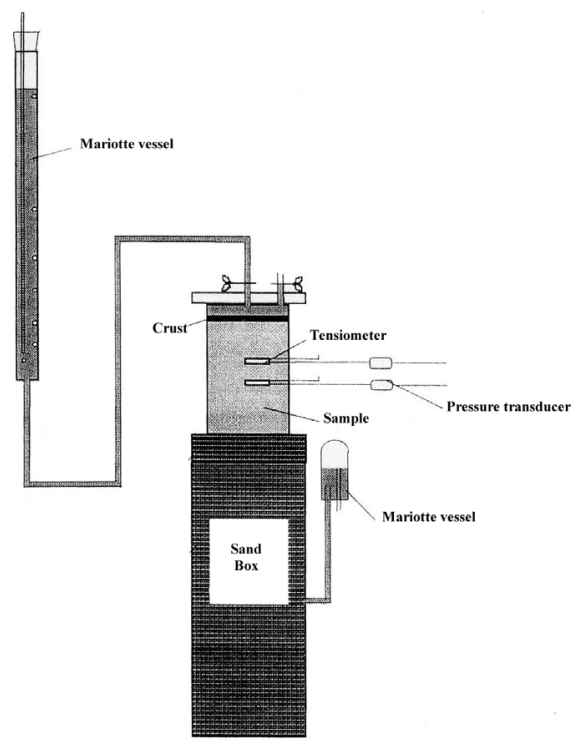

Figure 3: Apparatus for measuring soil hydraulic conductivity by crust method.

This method requires a pedestal of soil and a Stackman sand filter (figure 3) for draining the soil samples slowly saturated from the base. Conductivity values are determined during steady vertically downward flow under unit hydraulic 
gradient measured with small tensiometers. Once it has been ascertained that the water flux density in is equal to the water flux density out, the hydraulic conductivity will be equal to the imposed water flux. Moreover, it is worth noting that under the condition of unit hydraulic head gradient the matric potential at different depths is uniform, the water content is fairly uniform and, consequently, the accuracy in the estimate of $k$ will only depend on measurement errors. Thus, the function $k(h)$ of the soil in question was deduced with great accuracy, applying a series of steady water flux densities for an extended period of time by means of a porous disc connected to a bubble tower to control the water supply potential in a field of variation between 0 and $-0.20 \mathrm{~m}$ and evaluating the hydraulic gradient from the tensiometer measurements at depths of 0.025 and $0.075 \mathrm{~m}$.

\section{Results and discussion}

White and Sully [14]) calculate sorptivity by means of eqn. (2). By contrast, $Q_{\infty}$ is estimated for greater time values and the same authors use eqns. (6) and (7) to calculate the hydraulic conductivity. Thus, in using eqn. (6) $\Delta \theta$ is still required.

The main theoretical assumption underpinning the method is that cumulative infiltration $I$ for lower $t$ values varies linearly with the square root of time and, for greater values, linearly with $t$. figures $4 \mathrm{a}$ and $4 \mathrm{~b}$ show that for the soil in question the features of flow theory for disc permeameters are satisfied.
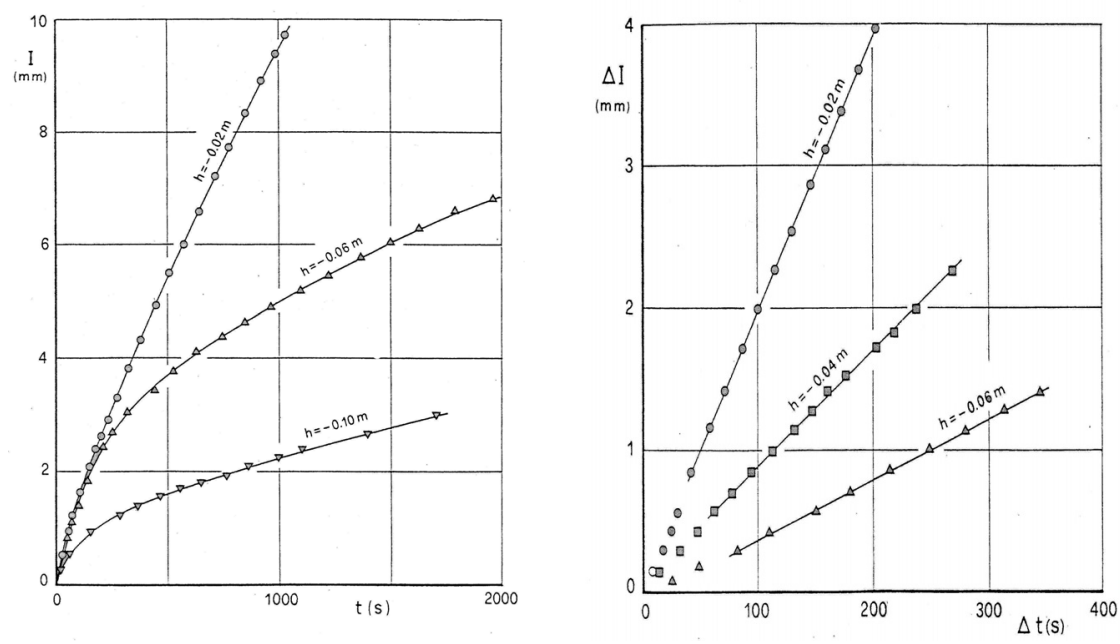

Figure 4: a) In situ cumulative infiltration over time and b) over square root of time, during 3-D flow from disc permeameter for 3 water supply potentials at 3 measurements sites.

Indeed, the above figures clearly show that for the 3 different water supply potentials, data quality is sufficient and that data are always widely available to 
determine $S_{o}$ by regression of $I$ against $t$ at the straight line portion of figure $3 \mathrm{~b}$ for $t$ values from 0 to roughly $100 \mathrm{~s}$. On the other hand, $Q_{\infty}$ may be evaluated by regression of $I(t)$ against $t$ for the long straight portion of figure $4 \mathrm{a}$. In the observed situation, it seems reasonable to expect a steady flow rate within less than an hour, which allows sufficient $Q_{\infty}$ data to be obtained most rapidly. This last consideration is interesting in the case where it is intended to conduct inquiries to ascertain the level and pattern of spatial or temporal variability.

Amongst the methods based on Wooding's equation (5), the method proposed by Ankeny et al. [12] is based only on measurements of steady-state flow rate $Q_{\infty}$. However, determining when $Q_{\infty}$ is reached may be very difficult (Warrick, [20]).

With regard to figure 5 , for the soil in question the mean time for reaching steady-state flow for the $-0.06 \mathrm{~m}$ water potential was $100 \mathrm{~s}$, followed by $400 \mathrm{~s}$ to attain steady-state flow at $-0.04 \mathrm{~m}$ water potential and finally $650 \mathrm{~s}$ for -0.02 water potential. In the above case, $Q_{\infty}$ is obtained by the regression of $I(t)$ against $t$ from figure 4 and eqns. (8) are used to calculate conductivity $k$.

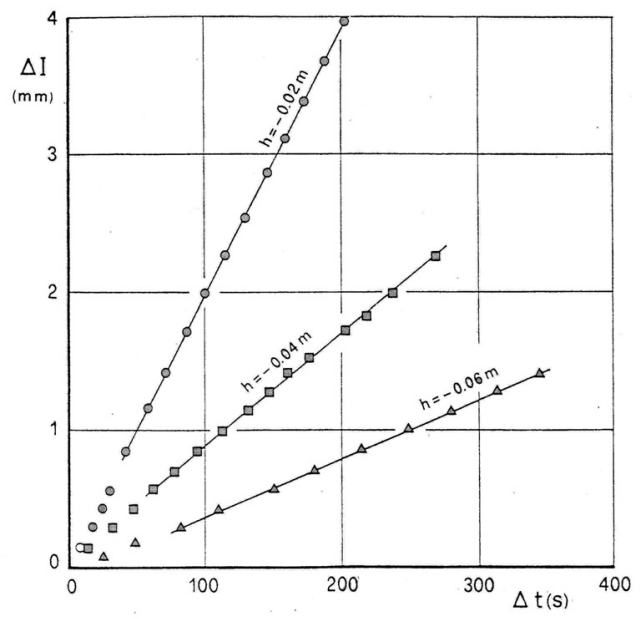

Figure 5: Steady-state flow intake for 3 water supply potential at the same measurement site.

Unlike the White and Sully method, in the Ankeny method measurements of $\theta_{0}$ and $\theta_{n}$ are entirely avoided.

The conductivity values calculated by the various methods adopted are given in figure 6, which also supplies, for the sake of comparison, laboratory core measurements of $k$ based on the crust method.

In particular, note that the $k$ values calculated by the Ankeny method are in good agreement with the $k$ values determined with the crust method. In any case, the bias ascertained for the White and Sully method to underestimate $k$ values is within less than one order of magnitude. 


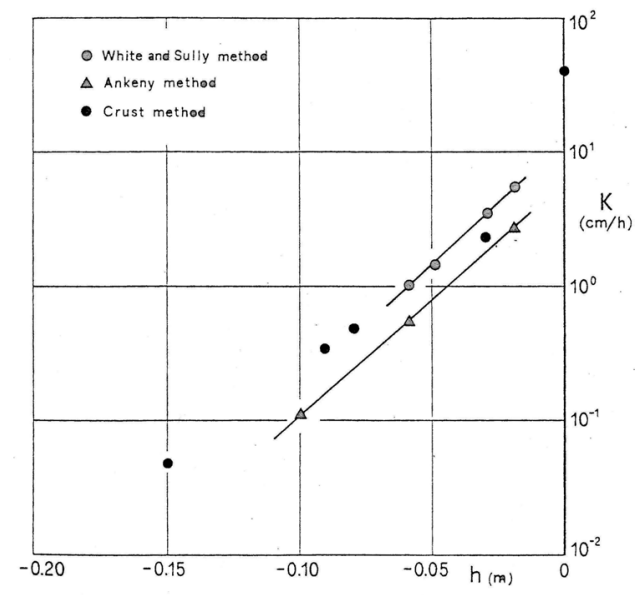

Figure 6: Comparison of estimates of unsaturated hydraulic conductivity obtained using White and Sully method [14]; Ankeny et al. method [12]; Boolting et al. method (=crust method) [13].

The analysis of behaviour at the origin of function $k(h)$ evidences a bimodal distribution of the porous system of the examined soil, with a water potential break-point at $\cong-0.03 \mathrm{~m}$. With the increase in water potential from $-0.02 \mathrm{~m}$ to 0 , hydraulic conductivity increases by about an order of magnitude, nonetheless assuming numerical values greater than those measured in a previous measuring campaign (Ciollaro et al., [24]) on undisturbed soil samples taken in the same sites. Such behaviour suggests that the structural porosity of this clay soil may play a dominant role in determining the pattern of water flow in the field.

Furthermore, to represent this bimodal pore system, a two-line regression model may be more responsive than the usual linear model, or than the model with several parameters proposed by van Genuchten [25]. Such findings were also reached by Messing and Jarvis [26] in a similar pedological context.

Philip [27], starting from macroscopic capillary length $\lambda_{c}$, infers a representative pore size $\lambda_{m}(\mathrm{~mm})$ by using the capillary theory:

$$
\lambda_{m}=\frac{\tau}{\rho g \lambda_{c}} \cong \frac{7.4}{\lambda_{c}}
$$

in which $\tau$ and $\rho$ are, respectively, the surface tension and the water density, and $g$ is the acceleration of gravity. The characteristic size $\lambda_{m}$ defined by White and Sully [14] to be a "physically plausible flow weighted pore size" may be considered a representative index of soil structure.

Starting from the measured values of $S_{0}, k$ and $\Delta \theta$, estimates were made by means of eqn. (9) of $\lambda_{m}$ values which are supplied in table 1 together with the values of $\lambda_{c}$ and $t_{\text {grav }}$. 
Table 1: $\quad$ Values of the physical and hydraulic properties of examined soil.

\begin{tabular}{|c|c|c|c|c|c|c|}
\hline $\begin{array}{c}\mathrm{h} \\
(\mathrm{m})\end{array}$ & $\begin{array}{c}\mathrm{S} \\
\left(\mathrm{mm} / \mathrm{s}^{1 / 2}\right)\end{array}$ & $\Delta \theta$ & $\begin{array}{c}\mathrm{k} \\
(\mathrm{mm} / \mathrm{s})\end{array}$ & $\begin{array}{c}\mathrm{t}_{\text {grav }} \\
(\mathrm{h})\end{array}$ & $\begin{array}{c}\lambda_{\mathrm{c}} \\
(\mathrm{mm})\end{array}$ & $\begin{array}{c}\lambda_{\mathrm{m}} \\
(\mu \mathrm{m})\end{array}$ \\
\hline-0.020 & 0.193 & 0.180 & 0.00697 & 0.17 & 13.1 & 572 \\
\hline-0.060 & 0.161 & 0.146 & 0.00154 & 3.04 & 64.4 & 118 \\
\hline-0.100 & 0.095 & 0.090 & 0.00035 & 21.20 & 122.6 & 61 \\
\hline
\end{tabular}

Examination of the table shows that the bimodal distribution is clearly evidenced by $\lambda_{m}$ which shows a 9-fold change between -0.02 and $-0.1 \mathrm{~m}$ water potential compared with a 5 -fold change between -0.02 and -0.06 water potential and only a 2 -fold change between -0.06 and $-0.1 \mathrm{~m}$ water potential. At $h>-0.06 \mathrm{~m}$ the influence of capillarity is very strong and $t_{\text {grav }}$ is large. However, macropore flow increases as $h$ approaches 0 and thus gravity flow is dominant at $h<-0.06 \mathrm{~m}$.

\section{Conclusions}

The Australian School of Soil Physics must take the credit for having made a great contribution in the analysis of multi-dimensional infiltration processes. Today, with a new class of experiments, it is possible to apply to the soil surface, via a porous membrane, a controlled water supply potential with water infiltrating according to Dirichlet's boundary condition. Infiltration is then evaluated as unsteady flow or it is possible to monitor the quasi-steady infiltration which follows the condition for which $d I / d t$ is constant. By then applying the theory of 3-D steady infiltration, soil hydraulic properties at or near saturation may be inferred, thereby breaking the existing link between gravity, capillarity and geometry of the disc source, as is evident in the analysis performed in section 2 of Materials and Methods.

With regard to the soil considered, the results obtained show good agreement between the methods used for determining hydraulic conductivity. The Ankeny et al. method [12] undoubtedly supplies the most accurate and reproducible results, and only requires steady state flows for 2 or 3 water supply potentials at the same locations, with the possibility of reducing the noise on $k(h)$ estimates caused by spatial variability. The bias of the White and Sully method [14] in underestimating $k$ could be attributed to the increasing spatial variability of hydraulic properties and previous volumetric water contents of the soil among the measuring sites. In situations of accentuated heterogeneity, as reported by Logsdon and Jaynes [28], the White and Sully calculations could even provide negative $k$ values.

In the light of the experience gained in this study, in the case of fine texture soils it would appear necessary to automatize the method, which would allow more accurate estimates of sorptivity. Finally, it is expected that there will be further and more extensive testing of the various methods, with a view to defining the hydrologic effects of soil structure, by using data from infiltration tests to be carried out on pedologically different soils. Such research efforts are clearly important for the quantitative assessment of soil management practices, soil irrigation and for studies of land degradation. 


\section{References}

[1] Beven K. and P. Germann, Macropores and water flow in soils. Water Resour. Res., 18, pp.1311-1325, 1982.

[2] Thomas G.W. and R.E. Phillips, Consequences of water movement in macropores. J. Environmental Qual., 8, pp. 149-152, 1979.

[3] White R.E., The influence of macropores in the transport of dissolved and suspended matter through soil. Adva. Soil Sci., 3, pp.95-120, 1984.

[4] Bouma J., Measuring hydraulic conductivity soil horizons with continous macropores. Soil Sci. Soc. Am. J., 46, pp. 438-441, 1982.

[5] Jarvis N.J.P., P.E. Janson, P.E. Dik and I. Messing, Modeling water and solute transport in macroporous soil, I, Model description and sensivity analysis, J. Soil Sci, 42, pp. 59-70, 1991.

[6] Chen C. and R.J. Wagenet, Simulation of water and chemicals in macropores soils, I. Representation of the equivalent macropore influence and its effect on soil-water flow. J. Hydrol, 130, pp. 105-126, 1991.

[7] Gerke H.H., and M.T. van Genuchten, A dual-porosity model for simulating the preferential movement of water and solutes in structured porous media, Water Resour. Res., 29, pp. 305-319, 1993.

[8] Bouma J. and L.W. Dekker, A case study on infiltration into dry clay soil, I. Morphological observations. Geoderma, 20, pp. 27-40, 1978.

[9] Warner G.S., I.D. Moore, J.L. Nieber and R.L. Geise, Characterization of macropores in soil by computer tomography. Soil Sci. Soc. Am. J., 53, pp. 653-660, 1989.

[10] Perroux K.M. and I. White, Designs for disc permeameters. Soil Sci. Soc. Am. J., 52, pp. 1205-1214, 1988.

[11] Watson K.W. and R.J. Luxmoore, Estimating macroporosity in a forest watershed by use of a tension infiltrometer. Soil Sci. Soc. Am. J., 50, pp. 578-582, 1986.

[12] Ankeny M.D., M. Ahmed, T.C. Kaspar and R. Horton, Simple field method for determining hydraulic conductivity. Soil Sci. Soc. Am. J., 55, pp.467-470, 1991.

[13] Booltink H.W.G., J. Bouma and D. Gimenez, Suction crust infiltrometer for measuring hydraulic conductivity of unsaturated soil near saturation. Soil Sci. Soc. Am. J., 55, pp. 566-568, 1991.

[14] White I. and M.J. Sully, Macroscopic and microscopic capillary length and time scales from field infiltration. Water Resour. Res., 23, pp. 15141522, 1987.

[15] Smettem K.R.J. and B.E. Clothier, Measuring unsaturated sorptivity and hydraulicc conductivity using multiple disc permeameters. J. Soil Sci., 40, pp. 563-568, 1989.

[16] Philip J.R., Theory of infiltration. Advances in Hydroscience, 5, pp. $215-$ 296, 1969.

[17] Philip J.R., A linearization change for the study of infiltration. In Water in the unsaturated zone. UNESCO Symp, pp. 471-478, 1966. 
[18] Philip J.R., Linearized unsteady multidimensional infiltration. Water Resour. Res., 22, pp. 1717-1727, 1986.

[19] Raats P.A.C., Analytical solutions of a simplified flow equation. Trans. Am. Soc. Agric. Eng., 19, pp. 683-689, 1976.

[20] Warrick A.W., Models for disc infiltrometers. Water Resour. Res., 28, pp.1319-1327, 1992.

[21] Gardner W.R., Some steady-state solutions of the unsaturated moisture flow equation with applications to evaporation from a water table. Soil Sci., 85, pp. 228-232, 1958.

[22] Wooding R.A., Steady infiltration from a shallow circular pond Water Resour. Res., 4, pp. 1514-1522, 1968.

[23] Scotter D.R., B.E. Clothier and E.R. Harper, Measuring saturated hydraulic conductivity and sorptivity using twin rings. Aust. J. Soil Res., 20, pp. 295-304, 1982.

[24] Ciollaro G, V. Comegna and A. Sommella, Effeti delle lavorazioni meccaniche delle caratteristiche idrauliche dei suoli. Atti del V Convegno Nazionale AIGR, vol. I , pp. 23-32, 1993.

[25] van Genuchten M.Th., A closed-form equation for predicting the hydraulic conductivity of unsaturated soils. Soil Sci. Soc. Am. J., 44, pp. 892-898, 1980.

[26] Messing I., N.J. Jarvis, Temporal variation in the hydraulic conductivity of a tilled clay soil as a measured by tension infiltrometers. J. Soil Sci., 44, pp. 11-24, 1993.

[27] Philip J.R., Reply to Comments on "Steady infiltration from spherical cavities". Soil Sci. Soc. Am. J., 49, pp. 788-789, 1985.

[28] Logsdon S.D. and D.B. Jaynes, Methodology for determining hydraulic conductivity with tension infiltrometers. Soil Sci. Soc. Am. J., 57, pp. 1426-1431, 1993. 